http://dx.doi.org/10.18675/1981-8106.vol25.n48.p80-98

\title{
Produção acadêmica nacional sobre qualidade no ensino fundamental: mapeamento da concepção e seus indicadores ${ }^{1}$
}

\author{
National Academic Literature about quality in primary education: mapping \\ the conception and this indicators
}

\section{Producción académica nacional sobre la calidad en la enseñanza fundamental: mapeo de la concepción y sus indicadores}

\author{
Adriana Dragone Silveira' \\ Taís Moura Tavares" \\ Marcos Aurélio Silva Soares"II \\ ' Universidade Federal do Paraná, Paraná - Brasil. E-mail: adrianadragone@ufpr.br \\ "Universidade Federal do Paraná, Paraná - Brasil. E-mail: tavarestais@gmail.com \\ III Centro Universitário Internacional UNINTER, Paraná - Brasil. E-mail: \\ soaresmarcos@hotmail.com.br
}

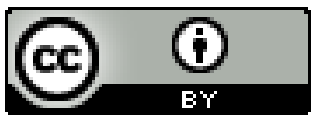

Educação: teoria e prática, Rio Claro, SP, Brasil - eISSN: 1981-8106

Está licenciada sob Licença Creative Common

\section{Resumo}

Este artigo tem como objetivo apresentar e analisar a produção acadêmica publicada no Brasil, no período de 1995 a 2012, referente ao tema da qualidade do ensino fundamental. Para uma organização sistemática e qualitativa das referências investigadas, optamos por realizar o levantamento de teses, dissertações e artigos consultando os sítios eletrônicos da

\footnotetext{
1 O artigo é uma versão revisada de trabalho apresentado no XXVI Simpósio Brasileiro de Política e Administração da Educação, realizado em Recife (2013), pela Associação Nacional de Política e Administração da Educação. O trabalho está vinculado ao projeto de pesquisa Qualidade na educação básica: uma leitura das condições de efetividade dos sistemas estaduais e municipais de ensino a partir de indicadores de financiamento, condições de oferta e resultados escolares, financiado pelo Observatório da Educação/CAPES, que objetiva realizar estudo sobre indicadores educacionais de qualidade no ensino fundamental, no Brasil.
} 
Capes, Scielo e Anped. Foram analisados 182 trabalhos por fonte de publicação, ano, instituição de pesquisa, região geográfica de vinculação dos autores, área de concentração das publicações, localidade de pesquisa e os indicadores de qualidade abordados. Na maioria das publicações o enfoque dado sobre a discussão da qualidade da educação ocorre por meio do fluxo e do desempenho educacional dos alunos nas avaliações em larga escala e ênfase na gestão e organização do trabalho escolar. Em alguns trabalhos está explícita a importância do conceito de educação de qualidade relacionar-se às finalidades às quais a educação se destina. Outros trabalhos destacam as condições materiais da escola; valorização dos trabalhadores em educação; a gestão e organização do trabalho pedagógico no interior da escola, assim como recursos adequados como fundantes para a almejada qualidade da educação.

Palavras-chave: Qualidade da educação; Ensino Fundamental; Indicadores de qualidade.

\begin{abstract}
This paper aims to present and analyze the academic literature on the topic of the quality of basic education, published in Brazil in the period 1995-2012. For a systematic and qualitative organization of references investigated, we chose to perform a survey of theses, dissertations, and articles querying the electronic sites Capes, Scielo and Anped. 182 studies were analyzed by source of publication, year, research institution, geographic region linking authors, area of concentration, location research and quality indicators discussed. In most publications the focus given on the discussion of the quality of education is linked to the flow and the educational performance of students in the large-scale assessments and emphasis on management and the organization of the school works. Some works are explicit the importance of the concept of quality education relate to the purposes to which education is designed. Other works punctuate the material conditions of school; valorization of the workers in education; management and organization of the pedagogical work within the school, as well as adequate resources that consolidate to the desired quality of education.
\end{abstract}

Keywords: Quality of education; Basic education; Quality indicators.

\title{
Resumen
}

Este artículo tiene como objetivo presentar y analizar la producción académica publicada en Brasil, en el período de 1995 a 2012, referente al tema de la calidad de la enseñanza fundamental. Para una organización sistemática y cualitativa de las referencias investigadas, optamos por realizar el levantamiento de tesis, disertaciones y artículos consultando los sitios electrónicos de la Capes, Scielo y Anped. Se analizaron 182 trabajos por fuente de publicación, año, institución de investigación, región geográfica de vinculación de los autores, área de concentración de las publicaciones, localidad de investigación y los indicadores de calidad abordados. En la mayoría de las publicaciones el enfoque dado sobre la discusión de la calidad de la educación ocurre por medio del flujo y del desempeño 
educacional de los alumnos en las evaluaciones en larga escala y el énfasis en la gestión y organización del trabajo escolar. En algunos trabajos está explícita la importancia de que el concepto de educación de calidad se relaciona a las finalidades a las que la educación se destina. Otros trabajos destacan las condiciones materiales de la escuela; valoración de los trabajadores en educación; la gestión y organización del trabajo pedagógico en el interior de la escuela, así como recursos adecuados como fundantes para la deseada calidad de la educación.

Palabras clave: Calidad de la educación; Enseñanza Fundamental; Indicadores de calidad.

\section{Introdução}

O tema da qualidade de ensino tem estado presente nas escolas, na mídia e nos órgãos gestores da educação e, também, em documentos das organizações internacionais. É, portanto, aspecto fundamental do direito à educação e está positivado na legislação brasileira que firma esse direito.

A Constituição Federal de 1988, dentre os princípios definidos para o ensino, afirma que se deve garantir "padrão de qualidade" (art. 206). Todavia, não definiu clara e objetivamente o que viria a ser qualidade. A definição de sentido acerca desse princípio avançou com aLei de Diretrizes e Bases da Educação Nacional, de 1996 (LDB/1996),que estabelece como padrões mínimos de qualidade de ensino: “[...] a variedade e quantidade mínimas, por aluno, de insumos indispensáveis ao desenvolvimento do processo ensinoaprendizagem" (art. $4^{\circ}$, inc. IX). Para assegurar o ensino de qualidade a LDB/96 determinou o estabelecimento pela União, com a colaboração dos Estados, do Distrito Federal e dos Municípios, de um "padrão mínimo de oportunidades educacionais para o ensino fundamental, baseado no cálculo do custo mínimo por aluno" (art. 74) (BRASIL, 1988, 1996).

Nesse movimento, tendo em vista a afirmação do direito à qualidade educacional, o Conselho Nacional de Educação (CNE), Câmara da Educação Básica (CEB), aprovou, em cinco de maio de 2010, o Parecer $n^{\circ} 8 / 2010^{2}$, que apresenta um projeto de Resolução que estabelece normas para a aplicação do inciso IX do art. $4^{\circ}$ da LDB, o qual dispõe sobre a viabilidade de o dever do Estado para com a educação escolar pública ser efetivado mediante a garantia de "padrões mínimos de qualidade de ensino, definidos como a variedade e quantidade mínimas, por aluno, de insumos indispensáveis ao desenvolvimento do processo de ensino-aprendizagem".Os padrões mínimos de qualidade para a educação pública têm como referência o Custo Aluno Qualidade Inicial (CAQi), desenvolvido pela Campanha Nacional pelo Direito à Educação (CARREIRA; PINTO, 2007).

Embora esse seja um tema recorrente, há pouco consenso sobre o que significa falar em qualidade na educação. Entretanto, é comum o princípio de que falar em direito à educação implica, necessariamente, na oferta de um ensino com qualidade. Tal fato se põe,

\footnotetext{
${ }^{2}$ Ainda não homologado pelo Ministro da Educação.
} 
dada a constatação que a universalização do ensino fundamental vem se fazendo com acentuado grau de desigualdade educacional entre redes e regiões do país. Realizado o direito ao acesso, põe-se a tarefa de definir padrões de qualidade que assegurem, respeitando as diversidades, a igualdade na realização do direito.

Segundo Oliveira e Araújo (2005), há três formas de percepção quanto à qualidade educacional:

[...] no Brasil, a qualidade de ensino foi percebida de três formas distintas. $\mathrm{Na}$ primeira, a qualidade determinada pela oferta insuficiente; na segunda, a qualidade percebida pelas disfunções no fluxo ao longo do ensino fundamental; e na terceira, por meio da generalização de sistemas de avaliação baseados em testes padronizados. (OLIVEIRA; ARAÚJO, 2005, p. 6).

Essas percepções correspondem a diferentes problemáticas que envolvem a educação escolar: o acesso, os mecanismos intraescolares de exclusão e a desigualdade na aquisição dos conhecimentos e formação de capacidades cognitivas. A cada uma delas correspondem diferentes medidas no sentido da equalização e da promoção da igualdade, por exemplo: mecanismos de distribuição da oferta de vagas e de acesso com a construção de equipamentos escolares; aperfeiçoamento dos processos de gestão; ou aprimoramento curricular e formação continuada. A todas elas se associa a questão do financiamento como requisito de aprimoramento das condições materiais das escolas e de valorização dos profissionais que nela atuam.

Como bem apontam Dourado e Oliveira, a definição de qualidade, termo polissêmico, se faz a partir de uma concepção de educação e de sociedade.

[...] qualidade é um conceito histórico, que se altera no tempo e no espaço, ou seja, o alcance do referido conceito vincula-se às demandas e exigências sociais de um dado processo histórico. Caso se tome como referência o momento atual, tal perspectiva implica compreender que embates e visões de mundo se apresentam no cenário atual de reforma do Estado, de rediscussão dos marcos da educação -como direito social e como mercadoria -, entre outros. (DOURADO; OLIVEIRA, 2009, p. 202-203).

No Brasil, os marcos legais da educação garantem a concepção de uma educação para todos, com base na democracia e na igualdade, decorrendo a preocupação com a definição de padrões que assegurem esses princípios, com base na atuação firme do Estado e com controle social crescente.

Partindo dessa concepção, este artigo tem como objetivo realizar levantamento bibliográfico a respeito da compreensão existente na produção acadêmica brasileira, mais recente, sobre a temática da qualidade. O procedimento realizado segue descrito, bem como a análise das temáticas associadas à questão da qualidade. 
Cabe, ainda, salientar os limites do que é aqui apresentado. Decidiu-se por iniciar o levantamento em 1995, de modo a captar as marcas da reforma educacional em curso. Entretanto, muitos dos materiais identificados nos bancos de dados não se encontraram disponíveis integralmente. Também,várias informações importantes para a análise da temática não foram encontradas nos resumos, pois ainda há pouca padronização nesse tipo de registro. A partir dessas limitações, apresentam-se, a seguir, os resultados alcançados.

O levantamentobibliográfico, a respeito da produção acadêmica relativa à qualidade da educação, está organizado neste artigo em três partes: a primeira descreve o processo e os procedimentos de coleta; a segunda apresenta os resultados que identificam a produção em relação ao período, instituições as quais os autores estavam vinculados, área geográfica; a terceira faz uma análise dos indicadores temáticos e volta-se ao conteúdo dos trabalhos acadêmicos.

\section{Procedimentos de coleta dos dados}

Inicialmente, para o levantamentodos dados a respeito da produção brasileira sobre a qualidadefoi necessário estabelecer os instrumentos de pesquisa que seriam utilizadose que permitissem uma organização sistemática e qualitativa das referências investigadas. Dessa forma, optou-se pela realização da pesquisa com base em teses, dissertações, artigos publicados no Brasil e disponíveis nos meios eletrônicos.

Nesse sentido, realizou-se o levantamento da produção científica publicada no Brasil em torno do tema da qualidade da educação disponível em meio eletrônico (internet) em três bases: banco de teses online da Coordenação de Aperfeiçoamento de Pessoal de Nível Superior $\left(\right.$ Capes $\left.^{3}\right)$, para a coleta das teses e dissertações defendidas no Brasil envolvendo a temática; Reuniões Anuais da Associação Nacional de Pós-Graduação e Pesquisa em Educação (Anped ${ }^{4}$ ) e a biblioteca eletrônica de artigos do ScientificElectronic Library Online $\left(\right.$ Scielo $\left.^{5}\right)$. O período definido para a coleta foi 1995-2012.

A escolha pela Capes para compor o banco de pesquisa se deu por esta instituição desempenhar papel fundamental na expansão e consolidação da pós-graduação stricto sensu (mestrado e doutorado) em todos os estados da federação. Também foi considerado o fator de que, em 2007, a Capes passou a atuar na formação de professores da educaçãobásica, ampliando o alcance de suas ações na formação de pessoal qualificado no Brasil e no exterior.

A opção por incluir a Anped no banco de pesquisa se deu pelo fato de entender que esta instituição ocupa um importante lugar no cenário nacional e internacional, em virtude da relevante produção científica de seus membros e da atuação política em defesa da qualidade da educação brasileira.

\footnotetext{
${ }^{3}$ Disponível em: http://www.capes.gov.br/servicos/banco-de-teses. Acesso em julho de 2012.

${ }^{4}$ Disponível em: http://www.anped.org.br/internas/ver/reunioes-anuais. Acesso em julho de 2012.

${ }^{5}$ Disponível em: http://www.scielo.org/php/index.php. Acesso em agosto de 2012.
} 
O terceiro meio eletrônico utilizado foi o Scielo, o qual contempla uma biblioteca eletrônica que abrange uma coleção selecionada de periódicos científicos brasileiros de diversas áreas.

A partir da definição dos meios eletrônicos a serem pesquisados, passamos a pensar os descritores que viabilizariam o levantamento qualitativo e quantitativo de dados possíveis sobre a temática: qualidade.

Foram organizados diversos descritores gerais (critérios comuns de busca), a saber: qualidade da educação; qualidade da escola; qualidade do ensino; qualidade do sistema; qualidade da educação básica; qualidade da política educacional; qualidade das políticas educacionais.

Além dos descritores gerais para cada uma das bases de dados: Capes,Anped e Scielo, foi preciso organizar um critério de busca diversificado, pois, em cada um deles, os critérios de pesquisa são diferenciados.

Ao realizar o primeiro levantamento com base nos descritores gerais e analisando os diversos critérios de pesquisa, optou-se por identificar, primeiramente, os títulos que poderiam indicar elementos que pudessem auxiliar no processo de fundamentação teórica. Para cada uma das bases de dados -Capes,Anped e Scielo- foi adotado procedimento diferenciado devido ao fato dos critérios de busca de cada um estar organizado de forma diferenciada. Realizou-se a cópia dos resumos dos textos selecionados na Capes, na Anpeda cópia dos textos na íntegra, visto que os mesmos não apresentavam resumo, e no Scielo foi obtida a cópia do texto na íntegra, porém os textos apresentam resumo já em seu início. Tal organização permitiu a visualização de um panorama inicial da literatura sobre a temática da qualidade.

No sítio eletrônico da Capes existem as seguintes opções para a pesquisa: por autor, por assunto, por instituição. Para as três opções existem também três indicadores: todas as palavras, qualquer uma das palavras e expressão exata. Optou-se por realizar a pesquisa por assunto, e, inicialmente, realizou-se o levantamento em dois indicadores: todas as palavras e expressão exata.Após o levantamento inicial dos dados decidiu-se por realizar a pesquisa com base no descritor: expressão exata. Foram acessados os 1.812 trabalhos sobre qualidade. E, ao aplicarmos os dois critérios escolhidos para seleção da amostra - a identificação no título com qualquer um dos sete descritores gerais e a leitura dos resumos, foram selecionados 128 textos sobre qualidade para compor a amostra de trabalhos da base de dados da Capes.

No portal eletrônico da Anped o levantamento de dados para a pesquisa foi realizado no Grupo de Trabalho 05 (GT05) Estado e Política Educacional, a partir da sua $23^{\mathrm{a}}$ sessão ${ }^{6}$ (2000). Aplicamos os mesmos descritores gerais definidos para a realização da pesquisa. Ao realizar o levantamento de dados no site da Anped foram acessados os 215 textos disponíveis no Grupo de Trabalho 05 (GT05) Estado e Política Educacional, em suas 12 sessões.

\footnotetext{
${ }^{6}$ Data do início dos trabalhos disponibilizados no portal.
} 
No entanto, o número de artigos encontrados no site da Anped, que atenderiam os descritores gerais, foi bem reduzido (4 trabalhos). Como identificamos no título dos textos palavras próximas ou que indicassem algo similar ao conceito de qualidade (equidade), este também foi incluído no momento da escolha dos textos pelo critério do título.

Sendo assim, optou-se por realizar a leitura de todos os títulos dos trabalhos publicados que atendessem um dos sete descritores gerais e incluímos, também, palavras próximas ou que indicassem algo similar ao conceito de qualidade (equidade). Isso resultou na leitura de resumos e da integralidade de 04 (quatro) textos sobre qualidade, porém o texto em que aparecia a palavra equidade foi descartado após a leitura e, ao final, foram selecionados 03 (três) artigos sobre qualidade para compor a amostra de textos do portal eletrônico da Anped.

Por fim, na base de dados do sítio eletrônico dabiblioteca Scieloexistem as seguintes opções de método para a pesquisa de artigos: Integrada; Por palavra; Por proximidade léxica e Google acadêmico e também, a possibilidade de escolha do local a ser pesquisado (onde).

Optou-se por realizar a pesquisa no método Integrada e,quanto à localidade (onde), a escolha foi por Brasil e não pelo indicador Regional.

Foram acessados os 3.046 artigos sobre qualidade. Ao aplicar os dois critérios escolhidos para seleção da amostra - a identificação no título com qualquer um dos sete descritores geraise a leitura dos resumos - selecionou-se 51 artigos que tratavam sobre qualidade.

Após a leitura de todo o material foram selecionadosapenas os que tratavam do tema qualidade envolvendo o ensino fundamental, considerando a temática da pesquisa mais amplaao qual se vincula este trabalho. Portanto, excluíram-se os trabalhos que tratavam exclusivamente da educação infantil, ensino médio, ensino superior, ensino profissional, rede privada. Nessa fase também foram eliminados os trabalhos disponíveis na Capes, mas que não continham o resumo e o acesso ao texto integral.

A partir desses critérios foram selecionados, nos sites da Capes, 128 trabalhos, sendo: 27 teses, 101 dissertações; na Anped, 03 artigos e, no Scielo, 51 artigos $^{7}$, totalizando 182 textos sobre qualidade para compor a análise deste artigo. Sendo composto de $54 \%$ de dissertações, $31 \%$ de artigos e $15 \%$ de teses.

Para a leitura dos materiais, inicialmente do texto completo, foi organizado um roteiro de leitura, contendo: dados gerais do artigo/trabalho; nível/etapa/modalidade de ensino; ano/período da investigação; local/abrangência geográfica da investigação; principais resultados da pesquisa; palavras-chave; indicadores da qualidade ${ }^{8}$ abordados na pesquisa/ensaio, sendo inicialmente os seguintes: finalidade da educação; democratização do

\footnotetext{
${ }^{7} \mathrm{O}$ único editorial encontrado na amostra de textos foi considerado, para efeito de contagem, como artigo.

"Além da multiplicidade de formas, os indicadores de qualidade devem ser dinâmicos e constantemente debatidos e reformulados, visto que as diversas expectativas e representações sociais integram um contexto histórico mais amplo e em constante movimento. Assim, a tarefa de definição dos indicadores de qualidade não é somente técnica, mas também política, ou seja, definir insumos e parâmetros para um ensino de qualidade requer uma análise dos custos, das condições reais, dos objetivos que se almeja e das expectativas sociais em torno do processo de escolarização" (OLIVEIRA; ARAUJO, 2005, p.18).
} 
acesso; fluxo; desempenho dos alunos; financiamento; aspectos do processo educacional, como: professor (salário/carreira, formação, condições de trabalho); gestão e organização do trabalho escolar; condições materiais da escola ${ }^{9}$.

Particularmente, em relação às teses e dissertações do banco de teses da Capes, a busca pelos textos em sua integralidade foi muito difícil. O trabalho inicial foi realizado por meio da leitura na íntegra das teses e dissertações, somente quando a sua localização não foi possível é que a realização do seu fichamento, para a elaboração do roteiro de leitura,se deu apenas pelo resumo.

Ao realizar a leitura dos textos e analisar os diversos descritores e critérios elencados para o fichamento da obra, pode-se considerar que encontrar uma definição/conceito de qualidade foi uma das tarefas das mais difíceis. Tal dificuldade corresponde à polissemia do termo, tal como apontada anteriormente por outros autores, como Oliveira e Araújo (2005) e Dourado e Oliveira (2009). A opção foi, então, por identificar indicadores que possibilitassem perceber a quais questões estávinculadaa ideia de qualidade quando tratada em relação à educação e ao trabalho da escola.

\section{Caracterização geral dos dados}

Com relação ao ano de publicação, segundo tipo de fonte, podemos perceber que há predominância de dissertações relativas ao tema da qualidade e que, entre os anos de 2003 a 2012, ocorre um maior número de publicações de estudos relativos à qualidade, eles totalizam $74,17 \%$ das teses, dissertações ou artigos publicados. Também é possível identificar que o ano de 2010 é o mais fértil em relação às publicações sobre qualidade, elas somam 17,03\% do total.

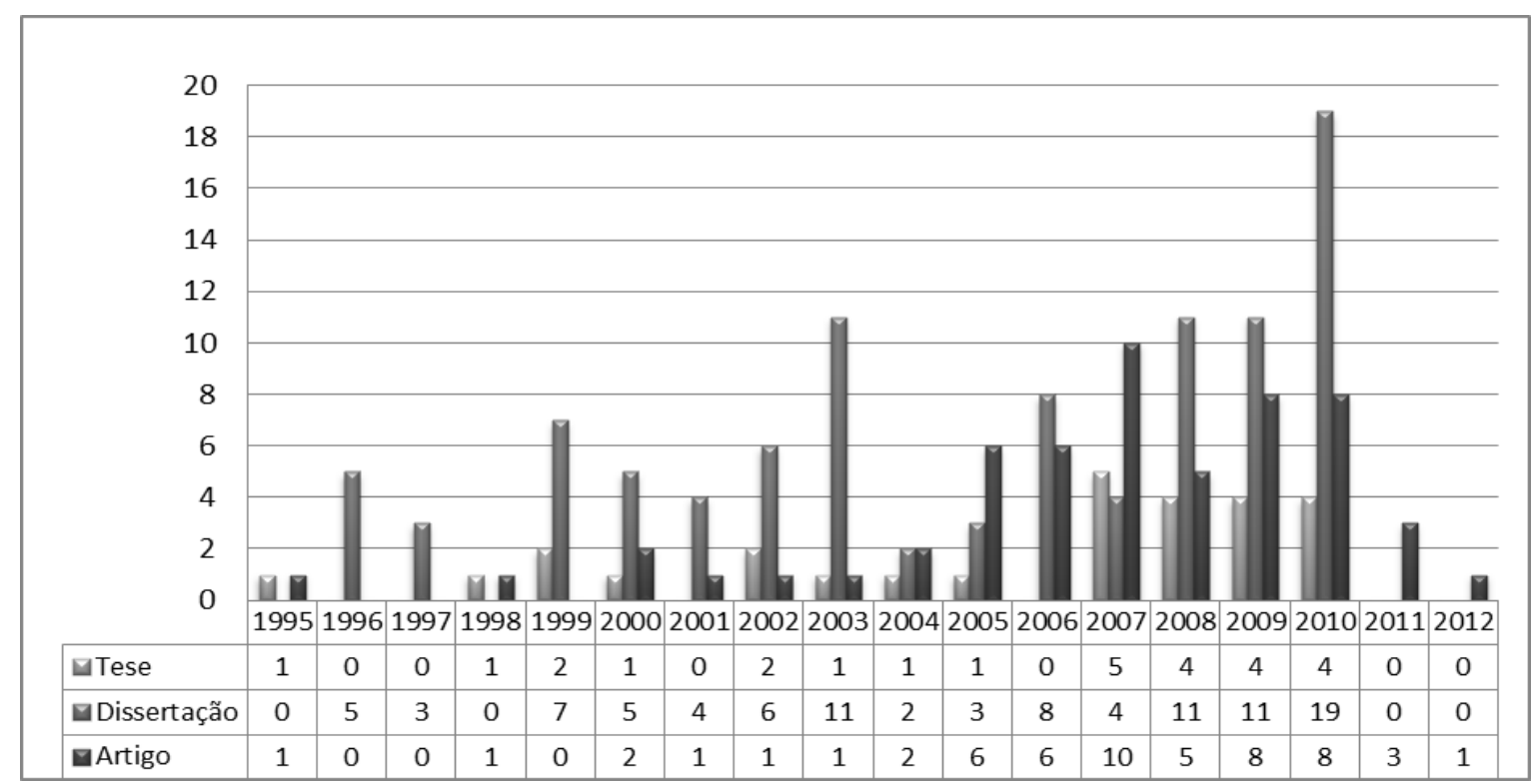

Gráfico 1 - Distribuição dos trabalhos por ano de publicação

\footnotetext{
${ }^{9}$ As dimensões gestão, professor e condições materiais da escola são eixos essenciais da pesquisa e compõem o Índice de Condições de Qualidade (ICQ) (SOUZA; GOUVEIA; SCHNEIDER, 2011).
} 
Fonte: os autores com base no levantamento dos dados.

Ao analisarmos a região geográfica da instituição dos autores é possível identificar que a maioria dos textos $(62,63 \%)$ provém da região sudeste. Percebe-se, também, que em todas as regiões o elemento qualidade é trabalhado, predominantemente, por dissertaçõesde mestrado. Um destaque importante é a baixa frequência de produção e investigação sobre qualidadena região norte, com apenas $1,64 \%$ da amostra selecionada. Fato que está relacionado, também, ao número de programas de pós-graduação nessas regiões.

Tabela 1 - Distribuição da produção acadêmica por região

\begin{tabular}{l|c|c|c|c}
\hline \multicolumn{1}{c}{ Região } & Tese & Dissertação & Artigo & Total por região \\
\hline Norte & 0 & 3 & 0 & 3 \\
Nordeste & 4 & 11 & 6 & 21 \\
Centro-Oeste & 1 & 10 & 6 & 17 \\
Sudeste & 20 & 52 & 42 & 114 \\
Sul & 2 & 23 & 2 & 27 \\
\hline
\end{tabular}

Fonte: os autores com base no levantamento dos dados.

Concomitante à análise da região geográfica da instituição dos autores, realizou-se a investigação sobre a vinculação dos autores com as instituições de pesquisa e, em particular, é possível identificar que a maioria da produção acadêmica sobre qualidade é realizada por meio de instituições públicas, totalizando $69,78 \%$ da amostra e as instituições privadas respondem a somente $26,92 \%$ dos estudos sobre qualidade. Pode-se observar, também, a participação de autores vinculados às instituições estrangeiras, em periódicos brasileiros, na reflexão sobre a qualidade do ensino, mas ela ainda é muito pequena, com apenas 3,29\% da amostra.

Dentre as instituições públicas analisadas, é preciso dar destaque a duas instituições. A primeira é a Universidade de São Paulo (USP), que possui 23 publicações, sendo 4 teses, 5 dissertações e 14 artigos, totalizando 12,63\% da amostra, e a segunda é a Universidade Federal de Pernambuco, com 13 publicações, sendo 3 teses, 6 dissertações e 4 artigos, totalizando $7,14 \%$ da amostra.

Tabela 2 - Distribuição do número de trabalhos por instituição de vinculação dos autores

\begin{tabular}{l|c|c|c|c}
\multicolumn{1}{c|}{ INSTITUIÇÕES } & Tese & Dissertações & Artigos & Total \\
\hline Universidades federais públicas & 11 & 43 & 22 & 76 \\
Universidades estaduais públicas & 12 & 20 & 17 & 49 \\
Instituições privadas & 4 & 37 & 8 & 49 \\
Universidades estrangeiras & 0 & 0 & 6 & 6 \\
Outras instituições públicas & 0 & 0 & 2 & 2 \\
\hline
\end{tabular}

Fonte: os autores com base no levantamento dos dados.

No processo de análise dos dados foi observada, também, a área de concentração das publicações e, nesse indicador, de modo geral, existe uma grande predominância da área de educação, com 76,92\% da amostra coletada. Se considerarmos que os estudos da área de avaliação fazem referência direta ao setor de educação, o índice fica ainda maior, com $80,21 \%$. Outras áreas que merecem destaque, porém com número muito singular de estudos, 
são: a economia, com 7,69\%; a administração, com 4,39\%; a área de política pública, com $3,84 \%$ da amostra.

Tabela3 - Distribuição do número de trabalhos por área de concentração

\begin{tabular}{l|c|c|c|c}
\hline \multicolumn{1}{c|}{ Área de concentração } & Tese & Dissertação & Artigo & Total \\
\hline Administração & 0 & 7 & 1 & 8 \\
Avaliação & 1 & 2 & 3 & 6 \\
Direito & 0 & 1 & 0 & 1 \\
Economia & 3 & 4 & 7 & 14 \\
Educação & 22 & 76 & 42 & 140 \\
Engenharia de Produção & 0 & 1 & 0 & 1 \\
Gestão Estratégia e Negócios & 0 & 1 & 0 & 1 \\
Política Pública & 1 & 4 & 2 & 7 \\
Psicologia & 0 & 0 & 1 & 1 \\
Química & 0 & 1 & 0 & 1 \\
Tecnologia & 0 & 2 & 0 & 2 \\
\hline
\end{tabular}

Fonte: os autores com base no levantamento dos dados.

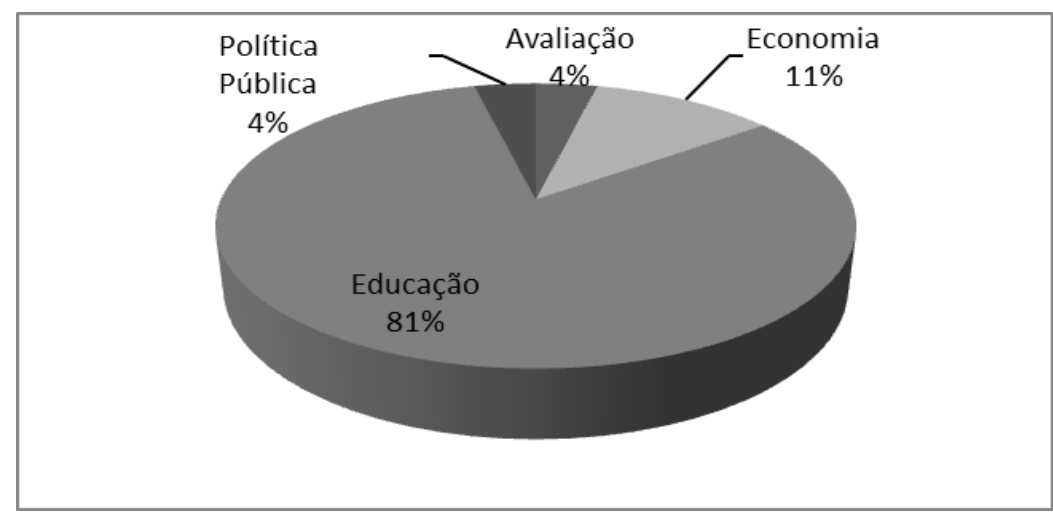

Gráfico 2 - Distribuição das teses por área de concentração Fonte: os autores com base no levantamento dos dados.

É possível perceber, em relação à referência de publicação tese,que as publicações ficam restritas a quatro áreas: educação, economia, avaliação e política pública. A área de educação possui a maior concentração de estudos publicados sobre qualidade (81\%). Outra área com maior índice de publicações, mas que, mesmo assim, fica muito distante da educação é a de economia, com $11 \%$ da amostra, mas com percentual significativo. As demais áreas avaliação e política pública contam cada uma com $4 \%$ das produções analisadas. 


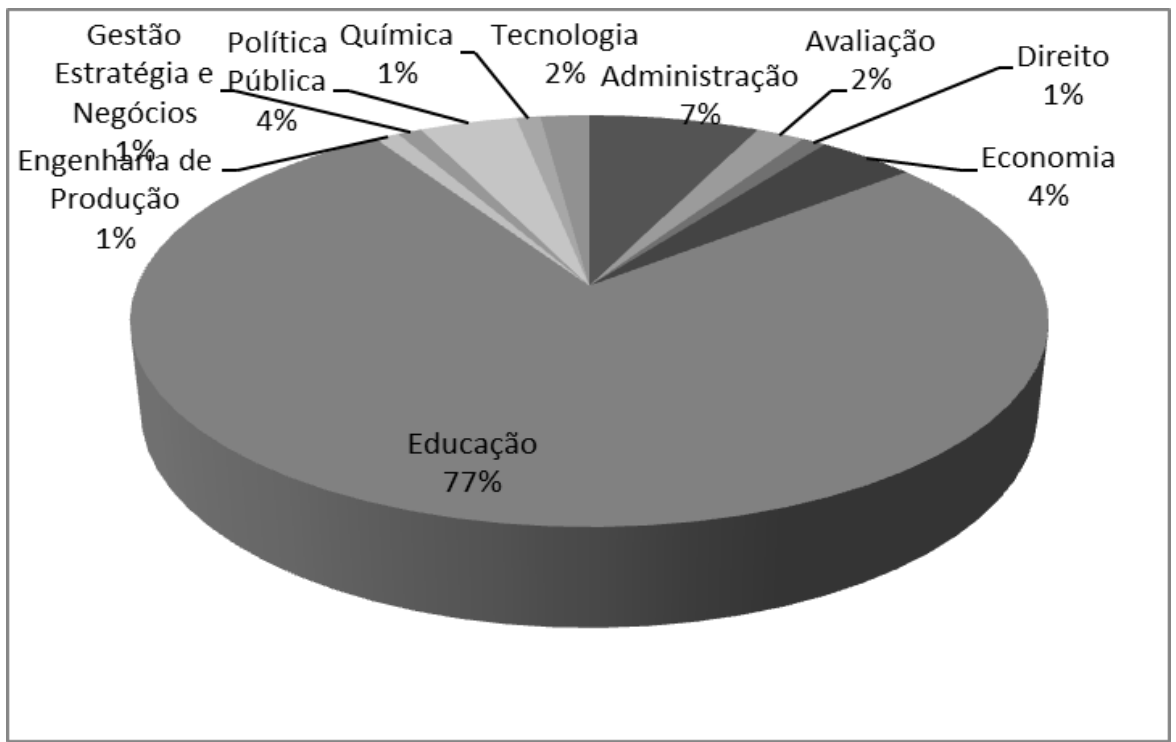

Gráfico 3 - Distribuição das dissertações por área de concentração

Fonte: os autores com base no levantamento dos dados

O mesmo não acontece em relação às dissertações que estão bem diluídas nas mais diversas áreas. A área de educação continua sendo a que possui a maior concentração de estudos publicados sobre qualidade, com $77 \%$ dos estudos e a outra área que merece destaque é a de administração, com $7 \%$ da amostra.

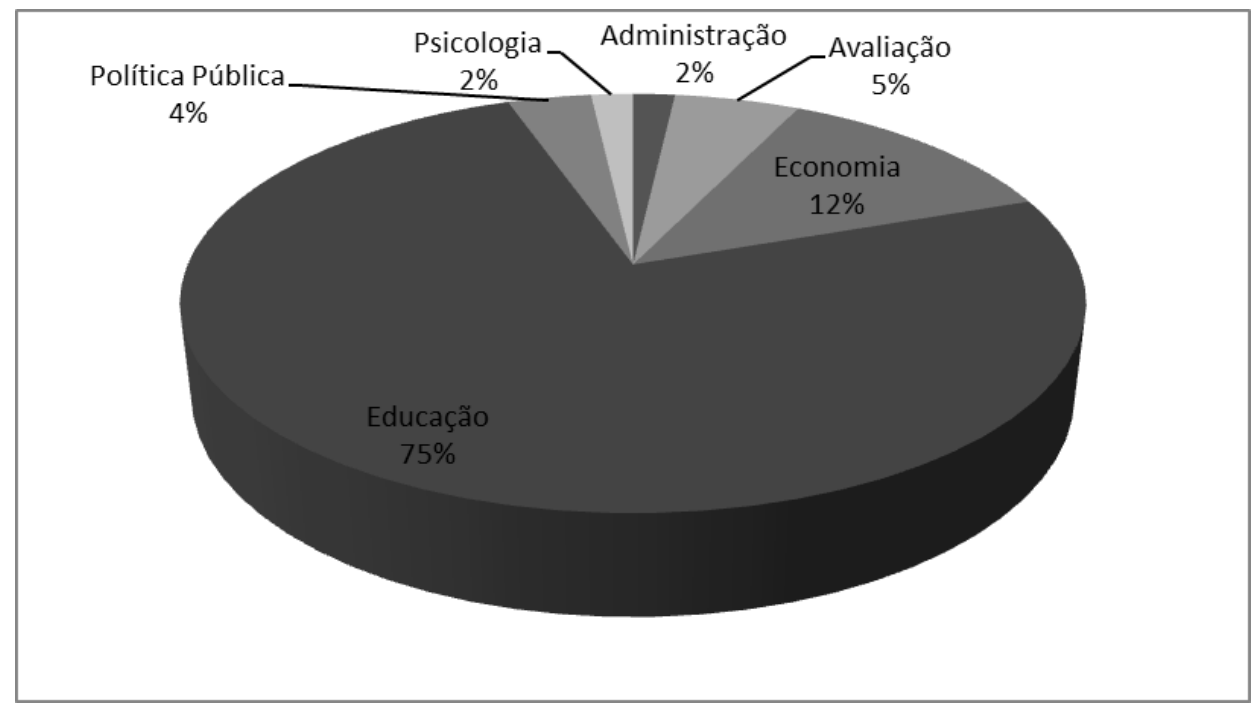

Gráfico 4 - Distribuição dos artigos por área de concentração Fonte: os autores com base no levantamento dos dados

Com relação aos artigos, percebe-se a concentração entre as áreas: educação, economia, avaliação, política pública, administração e psicologia. No entanto, a área de educação continua com a maior concentração de estudos sobre qualidade, $75 \%$ e a outra área com maior índice de publicações é a de economia, com $12 \%$ da amostra.

Com relação à abrangência geográfica das investigações,fica bem visível o problema identificado inicialmente, que é a falta da informação.Em $44 \%$ da amostra não foi possível a 
identificação do dado. No entanto, a circunscrição de estudo mais significativa continua sendo a dos estados.

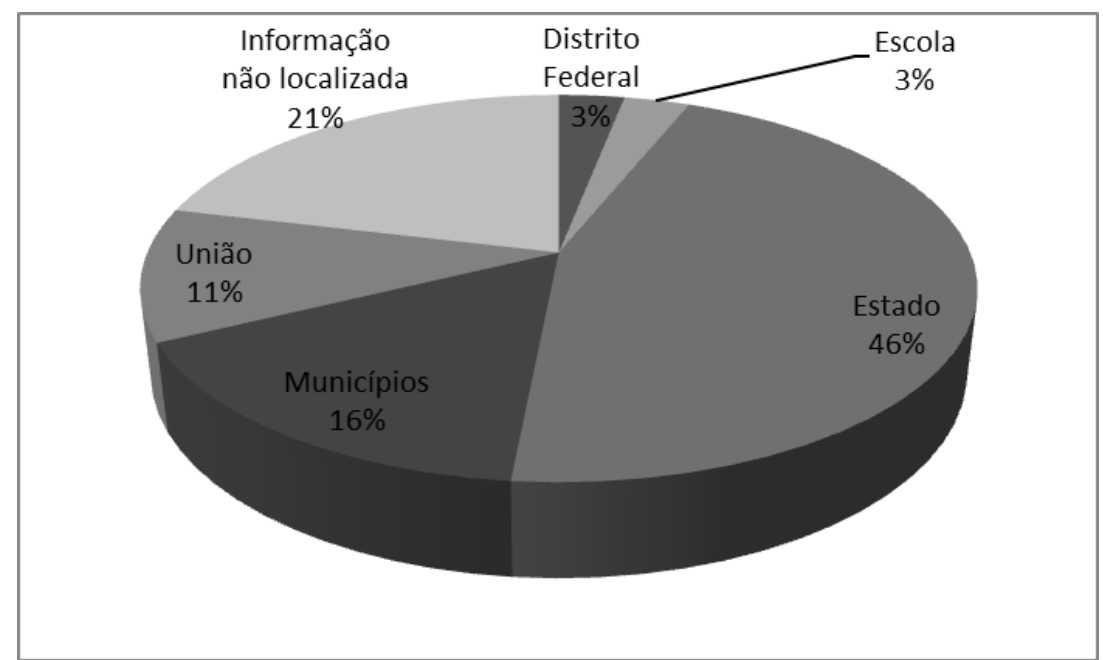

Gráfico 5 - Distribuição das dissertações por abrangência geográfica da investigação Fonte: os autores com base no levantamento dos dados

Nas dissertações, o dado mais significativo em relação à abrangência de estudo sobre qualidade são os estados, com $46 \%$ da amostra. Porém, o segundo dado mais relevante é a falta da informação sobre a abrangência do estudo, com $21 \%$ da amostra.

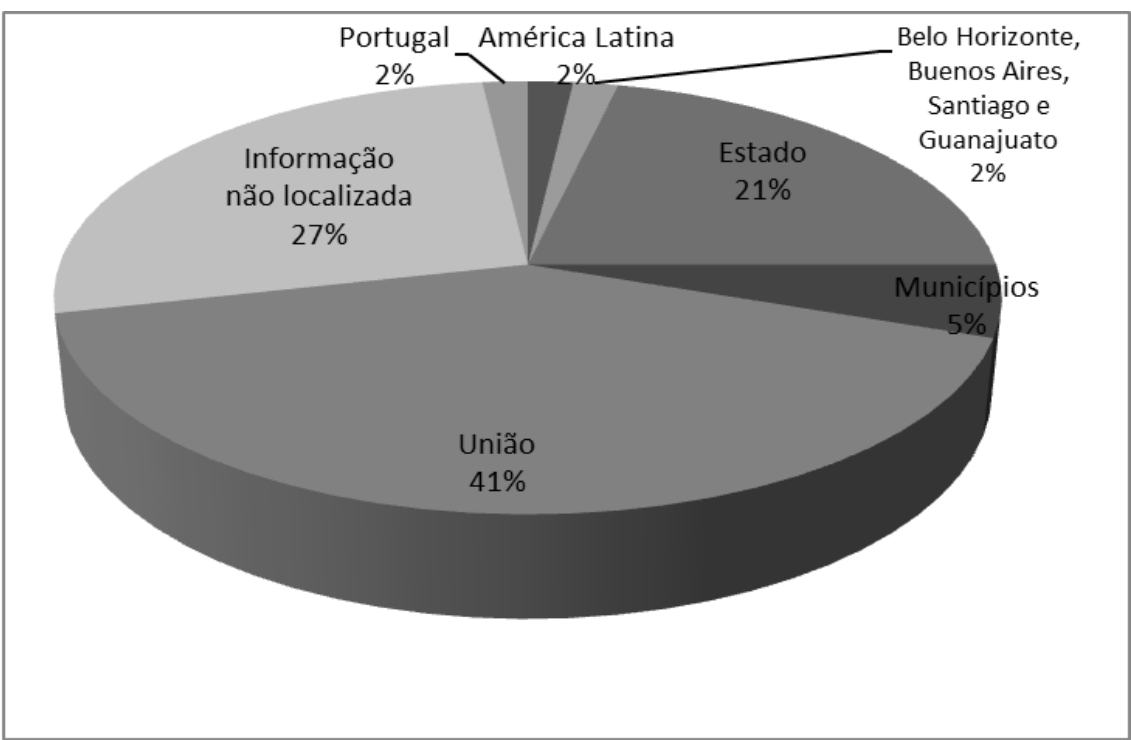

Gráfico 6 - Distribuição dos artigos por abrangência geográfica da investigação Fonte: os autores com base no levantamento dos dados.

Em artigos, o dado mais significativo em relação à abrangência de estudo sobre qualidade é o ente da federação União, com $41 \%$ da amostra. No entanto, dificuldade semelhante encontrada no dado referencia de publicação dissertação se repete em relação à referência artigo, o segundo dado mais relevante é a falta da informação sobre a abrangência do estudo, com $27 \%$ da amostra. 
Não foi possível identificar o período de insvestigação para 50\% da amostra, motivo pelo qual esse item foi descartado da análise.

\section{Análise Dos Indicadores Temáticos}

As teses, dissertações e artigos foram organizados, para fins de análise, por indicadores, segundo os temas tratados. Adotamos, como critério geral de classificação, o tema principal pelo qual o trabalho discutia a percepção da qualidade e o associamos a outros que também eram considerados no tratamento dos objetos específicos. Dessa organização resultou a tabela 4 .

Tabela 4 - Distribuição dos trabalhos por indicadores

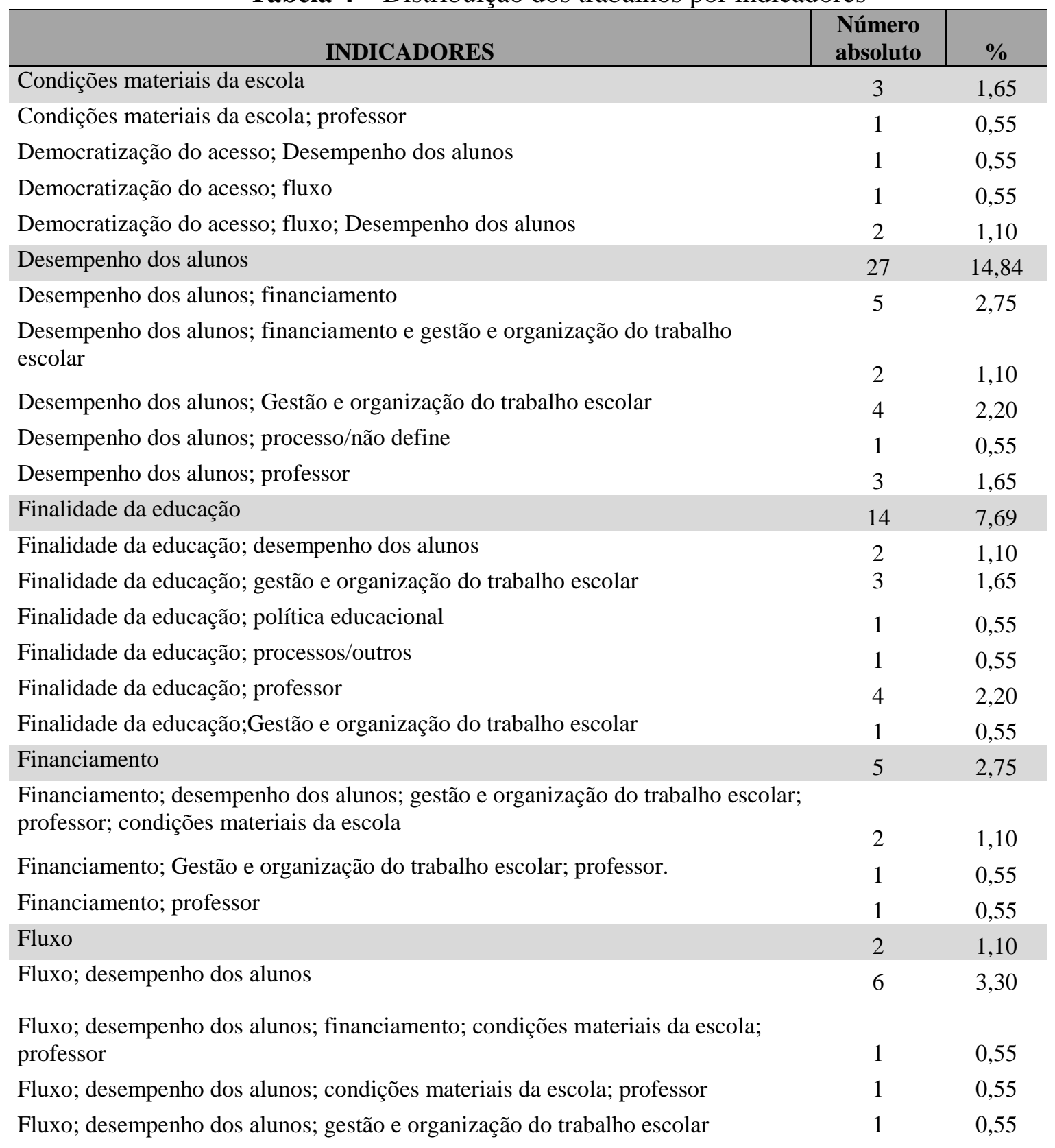


Fluxo; desempenho dos alunos; gestão e organização do trabalho escolar; condições materiais da escola

Fluxo; Gestão e organização do trabalho escolar

Gestão e organização do trabalho escolar

Gestão e organização do trabalho escolar; condições materiais da escola

Gestão e organização do trabalho escolar; Condições materiais da escola; professor

21,10

Gestão e organização do trabalho escolar; professor

Gestão e organização do trabalho na escola;professor; condições materiais da escola

$\begin{array}{ll}1 & 0,55 \\ 3 & 1,65\end{array}$

Informação insuficiente/não define

21,10

\section{Professor}

$3 \quad 1,65$

Professor; condições materiais da escola

Qualidade social

\begin{tabular}{|c|c|c|}
\hline Outros & 8 & 4,40 \\
\hline TOTAL DE TRABALHOS ANALISADOS & 182 & 100 \\
\hline
\end{tabular}

Fonte: os autores com base no levantamento dos dados

A definição desses indicadores temáticos fez-se a partir da relação entre os dados empíricos, ou seja, aquilo que estava descrito no material analisado. Embora expressos de outra forma, eles correspondem ao quadro apresentado por Dourado e Oliveira (2009) sobre os planos das dimensões intraescolares ${ }^{10}$ da qualidade de ensino: 1) plano do sistema - condições de oferta do ensino; 2) plano de escola - gestão e organização do trabalho escola; 3) plano do professor - formação, profissionalização e ação pedagógica; 4) plano do aluno - acesso, permanência e desempenho escolar.

Pela análise das temáticas, observa-se que as pesquisas sobre qualidade são marcadas pela influência dos eixos propostos pela reforma educativa da década de 1990. Segundo Casassus (2001), a reforma esteve orientada por três objetivos: 1) ampliação do financiamento, tendo em vista a centralidade da educação como estratégia de desenvolvimento; 2) mudanças na gestão; 3) melhoria da qualidade do aprendizado, para a qual os sistemas nacionais de avaliação deveriam servir como instrumento de monitoramento.

No gráfico 7fica demonstrado que a maior parte dos trabalhos sobre qualidade tem se articulado às temáticas da gestão e do desempenho dos alunos. Se agregarmos a esse último os trabalhos sobre fluxo, que também indica a qualidade do aprendizado os alunos, na medida em que tanto a repetência quanto o abandono dizem respeito ao desempenho escolar insatisfatório, a expressividade deste indicador é maior.

\footnotetext{
${ }^{10}$ Os autores também destacam as dimensões extraescolares envolvendo dois níveis: o espaço social e as obrigações do Estado (DOURADO; OLIVEIRA, 2009).
} 


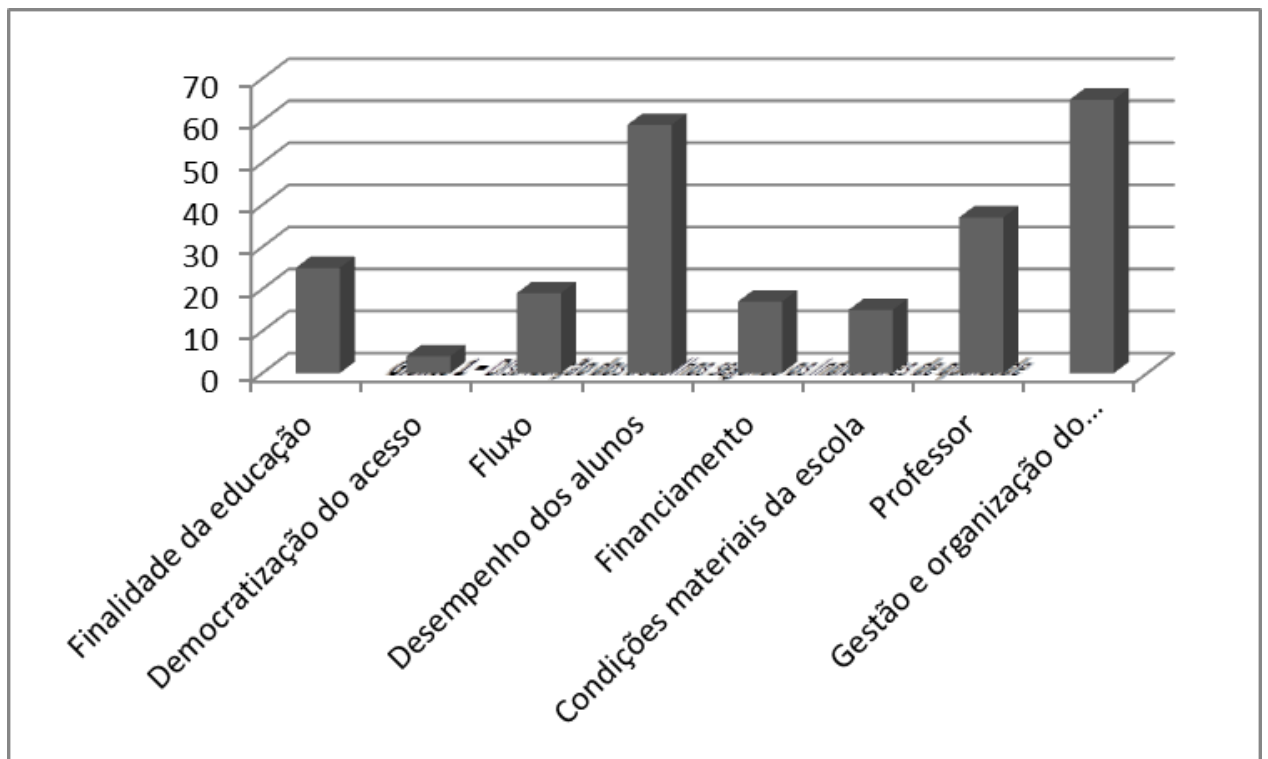

Gráfico 7 - Distribuição dos trabalhos segundo os indicadores de qualidade Fonte: os autores com base no levantamento dos dados

O espírito da reforma faz-se presente, também, na forma como esses temas são abordados. A temática da gestão, tratada como tema central em aproximadamente $25 \%$ das pesquisas. Todos os trabalhos analisados (65), que focaram principalmente a gestão, tratam da organização do trabalho escolar. Entendemos que isso é consequência da ênfase dada à descentralização para a unidade escolar, como a responsável pela qualidade do ensino, pelos documentos tanto dos organismos internacionais quanto por entidades e pelo governo nacional, desde a década de 1990. Isso se torna ainda mais nítido porque a organização do trabalho escolar aparece associada também em trabalhos que tratam de fluxo, financiamento, finalidade da educação e desempenho dos alunos.

Há grande diversidade na forma como o tema gestão é abordado. Como é recorrente na literatura, está associado às ideias de democracia, participação, autonomia e vários estudos tratam da participação dos segmentos da comunidade escola como, por exemplo, da família e da comunidade na qual a escola está inserida. Os papéis do diretor e do pedagogo/coordenador pedagógico são especificamente destacados em trabalhos sobre esse tema. Há, também, aqueles que tratam da qualidade total e de experiências específicas de gestão, como a Escola Plural. Alguns estão focados em processos organizativos, como o planejamento/planejamento estratégico/projeto político pedagógico, avaliação institucional, clima escolar. Outros enfatizam o trabalho pedagógico: aprendizagem, progressão continuada, reorganização curricular, programas de recuperação de aprendizagem.

No tratamento do tema professortambém é perceptível a influência da pauta dos anos 1990. Verifica-se que a responsabilização do docente pelo desempenho do aluno, presente em documentos que orientaram as reformas (CALDAS, 2011; DIAS; LOPES, 2003; GARCIA; ANADON, 2009), permanece influenciando a investigação sobre qualidade do ensino e da educação. Em torno de $12 \%$ dos trabalhos com esse tema, o professor é objeto central e apenas em um há associação com o tema das condições materiais da escola. Por outro lado, é interessante observar que os trabalhos que tratam de financiamento incluem o professor como 
um dos focos de pesquisa, associando qualidade às condições de valorização do professor: formação, salário, carreira e condições de trabalho. Também, um dos trabalhos sobre fluxo e um dos sobre gestão associam professor e condições materiais.

Financiamento é um tema com frequência em torno de $9 \%$, analisando principalmente a política de Fundos (FUNDEF e FUNDEB). Embora seja um dos objetivos da reforma em 1990, e tenha sido objeto de intensa pressão por parte do movimento de educadores com o argumento de colocá-lo como fundamental na garantia da qualidade da educação, verifica-se que não é um dos temas mais tratados nas pesquisas sobre qualidade. Dos oito temas elencados no gráfico8, fica em $5^{\circ}$ lugar, com $8,79 \%$, quase o mesmo de condições materiais $(8,25 \%)$ e acima de temas pouco tratados, democratização do acesso e qualidade social.

Tratam de desempenho e de fluxo como temas principais, em torno de $32 \%$ das pesquisas. Se considerarmos, além dessas, aquelas pesquisas que tomaram desempenho e fluxo relacionados a outros temas, o percentual chega a quase $44 \%$. Isso indica que a organização do sistema nacional de avaliação tem sido importante indutor das políticas e das investigações no campo acadêmico. $\mathrm{O}$ tema está vinculado também às discussões sobre financiamento, condições materiais da escola e, como já vimos, aos temas da gestão/organização do trabalho da escola, condições materiais e professor.

Aproximadamente $14 \%$ dos trabalhos são de natureza mais teórica e ensaística e tratam da finalidade da educação. Associam-se a um conjunto bastante diverso de outros temas: desempenho do aluno, gestão e organização do trabalho escolar, política educacional e professor. As abordagens tratam do tema numa perspectiva mais universal (emancipação humana, democracia, direito social e qualidade de ensino, justiça e equidade, acesso ao conhecimento) e também de modo focado, por exemplo, nas questões de gênero.

Um tema que parece superado quando se discute qualidade é o da democratização do acesso. Apenas quatro trabalhos tratam dessa questão e todos a articulam aos temas do desempenho do aluno e ao fluxo escolar. Isso se deve, provavelmente, ao fato de que o ensino fundamental encontra-se praticamente universalizado no Brasil.

Também qualidade social é um tema secundário, aparecendo em apenas dois trabalhos. Ressalta-se que são os únicos textos centrados em uma conceituação de qualidade. Os demais tendem a tomar esse conceito como pressuposto e buscam, principalmente, trabalhar com indicadores que o revelem. Traçam, antes, um perfil do que seria essa qualidade em termos do funcionamento da escola e dos parâmetros do trabalho docente.

Enfim, agregando os dados sobre fluxo e desempenho e acrescentando aos temas centralmente tratados em cada trabalho os demais temas a eles associados, temos o gráfico 8 que aponta com evidência que a qualidade da educação está associada, nas pesquisas desenvolvidas de 1995 a 2012, a duas questões cruciais: a do fluxo/desempenho do aluno e a da gestão/organização do trabalho escolar. 


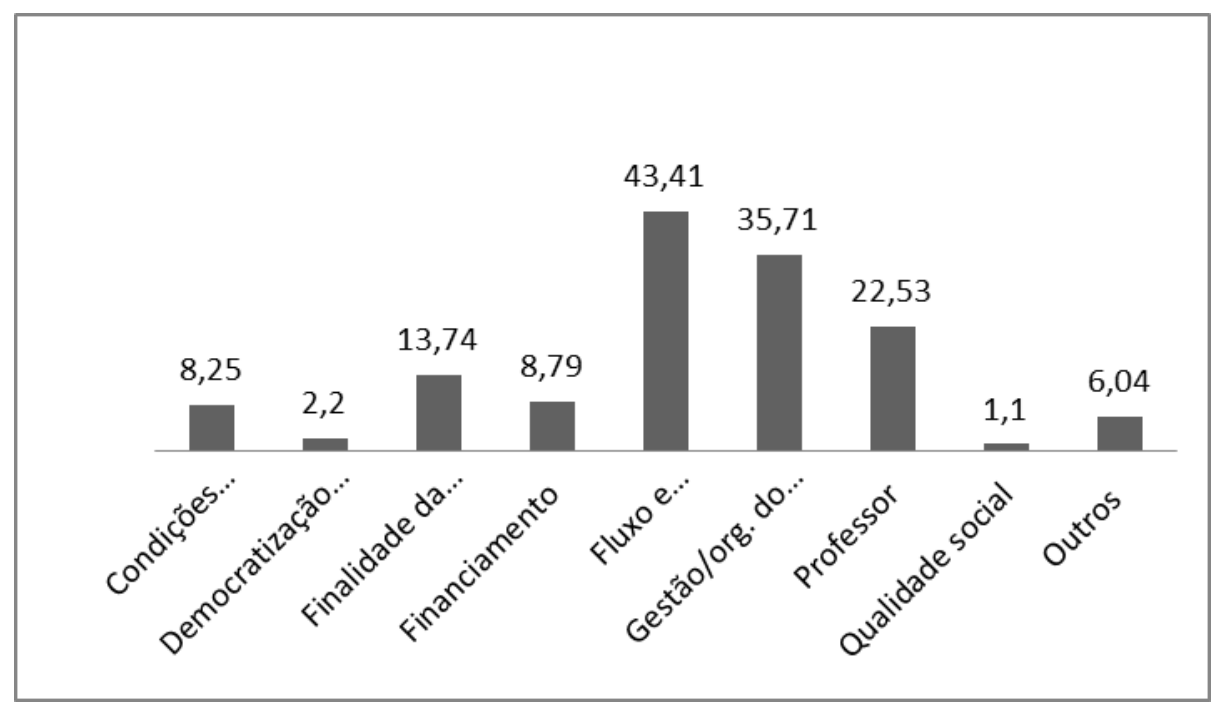

Gráfico 8 - Distribuição dos trabalhos segundo indicadores de qualidade Fonte: os autores com base no levantamento dos dados

Um conjunto de trabalhos trata de temas diversos que não puderam ser agregados. Compõem, como é possível ver no gráfico 8, em torno de $6 \%$ do material pesquisado. Abordam a qualidade da educação sobre a ótica de: pesquisa sobre Padrão de Vida (PPVIBGE): estudos econométricos acerca dos retornos para educação; legislação educacional; política educacional; o impacto da educação sobre a renda dos jovens no Brasil; relacionamento entre as três esferas de poder - União, estados e municípios; representações sociais de gênero das professoras sobre o magistério; expectativas dos pais em relação à escola.

\section{Considerações Finais}

A temática da qualidade da educação é presença constante nas discussões sobre a educação brasileira, no entanto o termo não possui o mesmo significado, como demonstrado na análise das produções acadêmicas pelos diferentes indicadorestratados nas pesquisas e ensaios.

Fica evidente o enfoque dado por parte das publicações sobre a mensuração da qualidade da educação por meio do fluxo e do desempenho educacional dos alunos nas avaliações em larga escala e ênfase na gestão e organização do trabalho escolar.

Em alguns trabalhos está explícita a importância do conceito de educação de qualidade relacionar-se às finalidades às quais a educação se destina.Outros trabalhos destacam as condições materiais da escola, a valorização dos trabalhadores em educação;a gestão e organização do trabalho pedagógico no interior da escola, assim como recursos adequados como fundantes para a almejada qualidade da educação.

Além da definição dos insumos mínimos e dos resultados desejáveis do processo educacional e da forma de medi-los, se faz necessário incorporar às dimensões do indicador 
de qualidade o que acontece no interior da escola, ou seja, os processos educativos "que têm valor formativo em si, e não que sejam apenas meios para se atingir outro objetivo, a proficiência" (OLIVEIRA, 2010, p.08). Assim, considerando que a qualidade educacional não pode ser reduzida aos resultados estudantis aferidos pelos sistemas de avaliação, autores como Souza, Gouveia e Schneider (2011) destacam a ideia de condições de qualidade como aquelas disponíveis para a realização.

Oferecer qualidade educacional é essencial para a garantia plena do direito à educação, como um direito fundamental, e para o exercício dos demais direitos. No entanto, para que a educação de qualidade não seja um privilégio de alguns, é preciso um sistema de ensino que garanta a todos o mesmo padrão de qualidade, e que contemple o acesso de todos à escola, sua permanência com sucesso, com a aprendizagem pelos alunos assegurando a equalização das oportunidades educacionais, com objetivo de eliminar as desigualdades e privações existentes na educação brasileira.

\section{Referências}

BRASIL. Constituição da República Federativa do Brasil de 1988, Brasília: Diário Oficial da União, 05/10/1988.

BRASIL. Casa Civil. Lei no. 9.394, de 20 de dezembro de 1996. Estabelece as Diretrizes e Bases da Educação Nacional. Disponível em: < http://www.presidencia.gov.br/ccivil_03/Leis/L9394.htm >. Acesso em: 20 jan. 2013.

CALDAS, A. do R. Profissionais da educação: entre o encantamento da resistência individual e o sofrimento do trabalho. In: SOUZA, Â.R.; GOUVEIA, A.B.; TAVARES, T. M. (Orgs.). Políticas educacionais: conceitos e debates.Curitiba: Appris, 2011. p. 189-209.

CARREIRA, D., PINTO, J.M.R. Custo Aluno Qualidade Inicial: rumo à educação pública de qualidade no Brasil. São Paulo: Global, Campanha Nacional pelo Direito à Educação, 2007.

CASASSUS, J. A reforma educacional na América Latina no contexto de globalização.

Cadernos de Pesquisa, São Paulo,n.114, p. 7-28, Nov. 2001.

DIAS, R.E.; LOPES, A.C. Competências na formação de professores no Brasil: o que (não) há de novo.Educ. Soc. Campinas, v.24, n.85, p. 1155-1177,2003.

DOURADO, L.F.; OLIVEIRA,J.F. de. A qualidade da educação: perspectivas e desafios. Cadernos Cedes, Campinas, v.29, n.78, p.201-215, Ago. 2009.

GARCIA, M.M.A.; ANADON, S.B.Reforma educacional, intensificação e autointensificação do trabalho docente.Educ. Soc., Campinas, v.30, n.106, p.63-85, Abr. 2009. 
OLIVEIRA, R.P. de; ARAUJO, G.C. de. Qualidade do ensino: uma nova dimensão da luta pelo direito à educação. Rev. Bras. Educ., Rio de Janeiro, n.28, inserir p.5-23, Abr.2005.

OLIVEIRA, R.P. de; A qualidade do ensino como parte do direito à educação: um debate em torno dos indicadores. Prova de concurso de professor titular Usp. São Paulo: Feusp, 2010 .

SOUZA, A.R. de; GOUVEIA, A.B.; SCHENEIDER, G. Índice de condições de qualidade educacional: metodologia e indícios. Estudos Avaliação Educacional. São Paulo, v. 22, n. 48, p. 115-136, Jan./Abr. 2011.

Recebido em: março 2014

Aprovado para publicação em: dezembro 2014 